\title{
Laparoscopic Examination and Transabdominal Preperitoneal (TAPP) Approach with Biologic Mesh for Strangulated Direct Inguinal Hernia Accompanied by Small Intestinal Perforation
}

\section{Tianhao Xie}

Affiliated Hospital of Hebei University https://orcid.org/0000-0003-3993-2190

Shujie Cheng

Affiliated Hospital of Hebei University

Yan Fu

Baoding First Central Hospital

Xinli Sun

Affiliated Hospital of Hebei University

Xiangxiang Ren

Affiliated Hospital of Hebei University

Jing Zhang

Affiliated Hospital of Hebei University

\section{Xiaojie Ren}

Laishui County Hospital

Xiaoshi Jin ( $\nabla$ doctorjinxiaoshi@126.com )

Affiliated Hospital of Hebei University

\section{Methodology}

Keywords: inguinal hernia, strangulate hernia, TAPP, small intestinal submucosa, seroma

Posted Date: February 18th, 2021

DOI: https://doi.org/10.21203/rs.3.rs-225002/v1

License: (c) (7) This work is licensed under a Creative Commons Attribution 4.0 International License. Read Full License 


\section{Abstract}

Background A direct inguinal hernia is caused by a weakness or defect in the floor of the Hesselbach triangle. It is believed that direct hernias are less likely to strangulate than indirect hernias, because the neck of the direct hernia is wide enough to avoid strangulation. Approximately $8.6 \%$ of all incarcerated inguinal hernia contents can be returned to the abdominal cavity spontaneously after general anesthesia, and intestinal ischemia or necrosis was detected by laparoscopic examination in approximately $40.9 \%$ of cases. However, which surgical approach or mesh for an acutely incarcerated and strangulated groin hernia is still no consensus. We retrospectively enrolled 12 patients with incarcerated inguinal hernias accompanied by small intestinal perforation who underwent laparoscopic examination when the hernia content spontaneously returned into the abdominal cavity after induction of general anesthesia in our institution.

Results 1 of the 12 patients had developed temporary seroma; the other 2 had early postoperative pain. No evidence of hernia recurrence, chronic pain, infection, scrotal swelling, paralyticileus, persistent seroma, mortality, or any other complications were found during the follow-up. At 1 year and most recent follow-up, all patients were satisfied with the treatment outcome.

Conclusions It is a necessary to detect abdominal viscera when incarcerated inguinal hernia contents return to the abdominal cavity spontaneously after general anesthesia, and laparoscopic examination is an efficient method. Laparoscopic TAPP technique with biologic meshes is a feasible method to treat strangulated inguinal hernias accompanied by small intestinal perforation. To better understand whether TAPP or biologic mesh apply to strangulated inguinal hernia (especially enterectomy) and evaluate its wider application, this treatment will need to be tested in larger clinical trials.

\section{Background}

An inguinal hernia is an abnormal protrusion of abdominal tissue through an inguinal fascial defect. When the hernia contents are non-reducible and the blood supply is being cutting off, it develops into a strangulated inguinal hernia. The incidence rate of strangulated inguinal hernia ranges from $0.29-2.9 \%$, and the mortality rate ranged from 2.6-9\% [1]. When it occurs, emergency surgery is recognized as the only effective treatment [2]. However, which surgical approach or mesh for an acutely strangulated groin hernia is still no consensus [2]. A direct inguinal hernia is caused by a weakness or defect in the floor of the Hesselbach triangle. It is believed that direct inguinal hernias are less likely to strangulate than indirect inguinal hernias, because the neck of the direct hernia is wide enough to avoid strangulation.

Although there is no single standard repair technique for all inguinal hernias, the Lichtenstein approach or a laparo-endoscopic repair is considered optimal treatment techniques [3]. Previous research has shown that approximately $8.6 \%$ of all incarcerated inguinal hernia contents can be returned to the abdominal cavity spontaneously after general anesthesia, and intestinal ischemia or necrosis was detected by laparoscopic examination in approximately $40.9 \%$ of cases [4].

Herein, we report a case series of strangulated direct inguinal hernia accompanied by small intestinal perforation that was managed at Affiliated Hospital of Hebei University, Baoding, China. In all cases, laparoscopic examination was performed when the hernia content spontaneously returned into the abdominal cavity after induction of general anesthesia. We repaired the hernias using the transabdominal preperitoneal (TAPP) technique with biologic meshes from porcine small intestinal submucosa.

\section{Materials And Methods}

Patients with incarcerated inguinal hernias accompanied by small intestinal perforation who underwent laparoscopic examination when the hernia content spontaneously returned into the abdominal cavity after induction of general anesthesia in our institution were included in this study. The preoperative diagnosis was made based on a history of unilateral or bilateral inguinal irreducible hemispherical bulge associated with bellyache and tender as described by the patients, and was confirmed by physical examination. All patients were diagnosed as an incarcerated inguinal hernia by ultrasound examination and computed tomography (Fig. 1),and were performed emergency surgery. Small intestinal perforation was detected and sutured $\square$ and hernias were repaired using the TAPP technique with biologic meshes from porcine small intestine submucosa during the operation. This was a retrospective review, but informed consent for the surgical procedure was obtained from all patients before surgery and the institutional review board approved the surgery and study. 
From January 2014 to January 2019, 12 Patients with incarcerated inguinal hernias accompanied by small intestinal perforation were enrolled in this review. Clinical data was collected about sex, age, BMI, duration of incarceration, ASA score, laterality, hernia size, postoperative complications (including early postoperative pain in the inguinal region, recurrence, chronic pain, infection, scrotal swelling, paralyticileus, seroma, mortality), drainage tube removal time.

\section{Surgical Procedure}

The patient was placed in the supine position. When the hernia content spontaneously returned into the abdominal cavity after induction of general anesthesia, the infraumbilical incision was taken and then a $30^{\circ}$ optical laparoscope was introduced through a 10-mm trocar. Two additional 5-mm operative trocars were placed on the right and left sides of the rectus abdominis muscle at the level of the umbilicus, respectively. Laparoscopic examination showed that pyogenic fluids and purulent material spread over the surface of the small intestine and inside the peritoneum in the lower abdominal cavity and the pelvic cavity. Small intestinal perforation was detected after we cleaned the pus and upon checking the intestinal canal. Direct inguinal hernias were confirmed by observing the fascial defect located in the area medial to the inferior epigastric artery. The extent of contamination by intestinal content was relatively minor at the peritoneum surrounding the hernia ring and hernia sac in all cases, because the operation was performed immediately after the hernia content returned into the abdominal cavity.

After washing with plenty of normal saline, we sutured the perforation of the small intestine using a 3/0 prolene (Ethicon, New Jersey, America) and repaired the hernias using the TAPP technique with biologic meshes from porcine small intestine submucosa (Biodesign/surgisis, Cook medical, Indiana, America); the hernia rings were subsequently sutured by using 2 - 0 slow-absorbing barbed sutures(Stratafix, Ethicon, New Jersey, America). Before closing the peritoneum, a 12\# drainage tube was placed between the peritoneum and mesh through a trocar (Fig. 2). After closing the peritoneum, a 22\# drainage tube placed in the pelvic cavity.

All the surgical procedures were performed by the same surgeon with sufficient experience in laparoscopic TAPP technique.

\section{Postoperative Management}

Postoperative antibiotics and nutritional support were given. On postoperative fifth day, all patients vented and defecated normally, and had fluids by mouth. The drainage tube placed in the pelvic cavity was removed on postoperative seventh day. The drainage tubes placed between the peritoneum and mesh were removed when no seroma was confirmed by ultrasound examination and when less than $5 \mathrm{ml}$ of exudate were drained out from the drainage tubes for 2 consecutive days(Table 1, Fig. 3). 
Table 1

Postoperative time course of volume of the drainage tubes placed between the peritoneum and mesh $(\mathrm{ml})$

\begin{tabular}{|c|c|c|c|c|c|c|c|c|}
\hline Case & POD1 & POD2 & POD3 & POD4 & POD5 & POD6 & POD7 & POD8 \\
\hline 1 & 12 & 8 & 10 & 4 & 0 & $\mathrm{R}$ & & \\
\hline 2 & 22 & 16 & 15 & 10 & 3 & 3 & $\mathrm{R}$ & \\
\hline 3 & 32 & 36 & 15 & 13 & 9 & 5 & 3 & $\mathrm{R}$ \\
\hline 4 & 16 & 11 & 7 & 4 & 3 & $\mathrm{R}$ & & \\
\hline 5 & 18 & 15 & 21 & 11 & 4 & 1 & $\mathrm{R}$ & \\
\hline 6 & 21 & 15 & 8 & 3 & 2 & $\mathrm{R}$ & & \\
\hline 7 & 36 & 42 & 18 & 8 & 3 & 2 & $\mathrm{R}$ & \\
\hline \multirow[t]{2}{*}{8} & Left 23 & Left 19 & $\mathrm{P}$ & & & & & \\
\hline & Right 28 & Right 25 & & & & & & \\
\hline 9 & 11 & 10 & 0 & 0 & $\mathrm{R}$ & & & \\
\hline 10 & 21 & 15 & 9 & 3 & 0 & $\mathrm{R}$ & & \\
\hline 11 & 15 & 18 & 9 & 3 & 0 & $\mathrm{R}$ & & \\
\hline 12 & 35 & 42 & 21 & 13 & 11 & 4 & 2 & $\mathrm{R}$ \\
\hline
\end{tabular}

\section{Results}

The clinical characteristics of the patients and postoperative outcomes are shown in Table 2 . There were 10 males and 2 females in this study, with a male-to-female ratio of 5:1. The patients ranged in age from 53 to 71 years, with a median age of $60.2 \pm 5.0$ years. Mean follow-up period was $19.3 \pm 5.4$ (range 13-28) months. 
Table 2

Characteristics of patients and postoperative outcomes

\begin{tabular}{|c|c|c|c|c|c|c|c|c|c|c|}
\hline Case & Sex & Age & $\begin{array}{l}\text { BMI } \\
\left(\mathrm{kg} / \mathrm{m}^{2}\right)\end{array}$ & $\begin{array}{l}\text { Duration of } \\
\text { incarceration } \\
\text { (hours) }\end{array}$ & $\begin{array}{l}\text { ASA } \\
\text { score }\end{array}$ & Laterality & $\begin{array}{l}\text { Hernia } \\
\text { size(cm) }\end{array}$ & $\begin{array}{l}\text { Postoperative } \\
\text { complications }\end{array}$ & $\begin{array}{l}\text { Drainage } \\
\text { tube } \\
\text { removal } \\
\text { time (days) }\end{array}$ & $\begin{array}{l}\text { Follow- } \\
\text { up } \\
\text { (months) }\end{array}$ \\
\hline 1 & Male & 54 & 26 & 7 & 口 & Right & 2.1 & - & 6 & 24 \\
\hline 2 & Male & 63 & 29 & 8 & प & Right & 1.3 & - & 7 & 19 \\
\hline 3 & Male & 64 & 26 & 5 & 口 & Left & 1.6 & $\begin{array}{l}\text { early } \\
\text { postoperative } \\
\text { pain }\end{array}$ & 8 & 27 \\
\hline 4 & Male & 56 & 24 & 4 & प & Right & 1.7 & - & 6 & 28 \\
\hline 5 & Female & 62 & 25 & 10 & $\square$ & Right & 1.0 & - & 7 & 15 \\
\hline 6 & Male & 58 & 27 & 4 & प & Left & 1.5 & - & 6 & 26 \\
\hline 7 & Male & 53 & 27 & 6 & $\square$ & Right & 1.6 & - & 7 & 16 \\
\hline \multirow[t]{2}{*}{8} & \multirow[t]{2}{*}{ Male } & \multirow[t]{2}{*}{62} & \multirow[t]{2}{*}{32} & \multirow[t]{2}{*}{3} & \multirow[t]{2}{*}{$\square$} & \multirow[t]{2}{*}{ Bilateral } & Left 3.5 & \multirow{2}{*}{$\begin{array}{l}\text { temporary } \\
\text { seroma }\end{array}$} & \multirow{2}{*}{$\begin{array}{l}3 \\
\text { (prolapsed) }\end{array}$} & \multirow[t]{2}{*}{18} \\
\hline & & & & & & & $\begin{array}{l}\text { Right } \\
1.0\end{array}$ & & & \\
\hline 9 & Male & 61 & 21 & 8 & प & Left & 2.2 & - & 5 & 15 \\
\hline 10 & Male & 71 & 24 & 9 & $\square$ & Right & 1.3 & - & 6 & 16 \\
\hline 11 & Female & 57 & 24 & 3 & $\square$ & Right & 1.5 & $\begin{array}{l}\text { early } \\
\text { postoperative } \\
\text { pain }\end{array}$ & 6 & 15 \\
\hline 12 & Male & 61 & 34 & 6 & प & Right & 1.7 & - & 8 & 13 \\
\hline
\end{tabular}

In one case, bilateral direct inguinal hernias were confirmed by laparoscopic examination (dimensions: $3.5 \mathrm{~cm}$ in diameter in the left and $1.0 \mathrm{~cm}$ in diameter in the right). The hernia ring and sac in the left was relatively clean; on the contrary, purulent material was detected in the right. From the evidence, we deduced that the small intestinal perforation was caused by the right incarcerated direct inguinal hernia (Fig. 2). However, we also repaired bilateral hernias with biologic meshes. On day 3 post-surgery, both drainage tubes prolapsed due to patient movement. The patient felt slight swelling in both inguinal areas, and ultrasound examination showed a collection of free fluid (dimensions: $4.4 \times 3.4 \times 1.3 \mathrm{~cm}$ in the left and $3.6 \times 2.6 \times 1.4 \mathrm{~cm}$ in the right) on day 5 . A seroma was considered, and observe treatment was given. The bowel recovered normal function, and no any discomfort after the patient had fluids by mouth. The free fluid area shrunk on day 20 (dimensions: $2.3 \times 1.7 \times 1.2 \mathrm{~cm}$ in the left and $2.1 \times 1.2 \times 1.1 \mathrm{~cm}$ in the right), and disappeared on day 37.

In two cases, early postoperative pain was complained on the first postoperative day and was significantly relieved after 2 days of analgesia therapy.

No evidence of hernia recurrence, chronic pain, infection, scrotal swelling, paralyticileus, persistent seroma, mortality, or any other complications were found during the follow-up. At 1 year and most recent follow-up, all patients were satisfied with the treatment outcome.

\section{Discussion}

When incarcerated inguinal hernia content returned to the abdominal cavity spontaneously after general anesthesia, the traditional options chosen by the surgeon tend to be treatments based on observation or an exploratory laparotomy. Hernia sac laparoscopy (hernioscopy) performed following insertion of a laparoscope through the hernia sac, is simple and accurate technique with the potential to prevent unnecessary laparotomies after spontaneous incarcerated inguinal hernia reduction $[5,6]$; however, this is the foundation for open surgery. 
The transabdominal preperitoneal approach, is a safe and effective surgical method for inguinal hernia [2], and can provide the best operative field of vision, sufficient time to observe the vital recovery of hernia contents (especially lustre and peristalsis of intestinal canal), and reduce unnecessary intestinal resection. In fact, the color change, the peristalsis and the vitality of the intestine, if in doubt, the intestinal vitality involved in incarceration, is definitely an advantage for open procedure, because the surgeon in the open procedure has less time to make a decision about whether to perform a bowel resection [7]. It is therefore recommended that repair of incarcerated hernias may be performed with a laparoscopic approach in the guidelines of the World Society of Emergency Surgery (WSES) [8, 9]. In our experience, we believe that use of laparoscopic examination is a reasonable method for two reasons: 1) we could accurately assess the condition of the small intestine, and sutured the perforation; 2 ) this approach established the foundation for TAPP. The risk of reoperation was avoided because the perforation was detected in a timely manner.

Mesh repair is recommended as the first choice, either by an open procedure or a laparo-endoscopic repair technique [2]. A well-done cohort study of Lichtenstein repairs in a clean-contaminated area (enterectomy vs. nonenterectomy) revealed that it was safe to repair acute incarcerated inguinal hernia using a non-absorbable mesh (monofilament polypropylene) with an acceptable rate of wound infection and recurrence [10]. However, there is no medical recommendation yet regarding the optimum choice of mesh for patients with of bowel perforation (contaminated-dirty area).

A biologic mesh is mainly composed of collagen, elastin, glycoprotein and mucin, which are an extracellular matrix fiber mesh scaffold. BioMesh Study Group did not recommend the routine use of biologic mesh under contaminated conditions, because the cumulative data regarding biologic mesh use in ventral hernia do not support the claim that it is better than synthetic mesh used under the same conditions [11]. Previous literature has expressed the effectiveness of the use of biologic mesh under contaminated conditions; unfortunately it included in reviews consisted low level of evidence [12].

In the guidelines of the WSES, biologic meshes may be a valid option for emergency hernia repair in contaminated-dirty surgical fields but merit a detailed cost-benefit analysis [9]. However biologic mesh can repair abdominal wall defects by stimulating endogenous tissue regeneration, and possesses more powerful anti-infection ability which is one of the main marketed described advantages of biologic meshes [13-15]. As early as 2002, Franklin et al. [16] reported for the first time the research of hernia repair with biologic meshes from porcine small intestinal submucosa in 25 cases of external abdominal hernia under contaminated or seriously contaminated environment; the average follow-up period was 15 months, and no complication related to the mesh and hernia recurrence was found. Later, patients were expanded to 53 cases, and the same results were still obtained after an average observation period of 19 months [17]. FitzGerald JF et al. [18] reported that the recurrence rate was significantly reduced when biological mesh used to reinforce the repair compared with used as a bridge. From the perspective of economics, Schneeberger et al. [19] reported that with the decrease of biologic mesh cost and the increase of long-term complications of synthetic mesh, biologic mesh was more economical and effective than synthetic mesh.

For these reasons, we sutured the hernia rings and chose biologic meshes to repair hernias in this research, and the results showed that the patient benefited from the treatment. Drainage tubes were placed between the peritoneum and meshes to prevent inflammatory infiltration and seroma formation. However, despite this minor complication ( 1 case of temporary seroma, 2 cases of early postoperative pain), the patient recovered steadily.

\section{Conclusion}

We report a case series of strangulated direct inguinal hernia accompanied by small intestinal perforation that was successfully managed with hernia repair by laparoscopic TAPP technique with biologic meshes from porcine small intestinal submucosa. It is a necessary to detect abdominal viscera when incarcerated inguinal hernia contents return to the abdominal cavity spontaneously after general anesthesia, and laparoscopic examination is an efficient method. Laparoscopic TAPP technique with biologic meshes is a feasible method to treat strangulated inguinal hernias accompanied by small intestinal perforation. To better understand whether TAPP or biologic mesh apply to strangulated inguinal hernia (especially enterectomy) and evaluate its wider application, this treatment will need to be tested in larger clinical trials.

\section{Abbreviations}

Transabdominal preperitoneal: TAPP; World Society of Emergency Surgery: WSES.

Page 6/11 


\section{Declarations}

\section{Ethics approval and consent to participate}

This study was approved by the Ethics Committee of The Affiliated Hospital of Hebei University, Baoding, Hebei, China.

\section{Consent for publication}

The participants have consented to the publication of this article.

\section{Availability of data and materials}

All data generated or analysed during this study are included in this published article.

\section{Competing interests}

The authors declare that they have no competing interests.

\section{Funding}

This study was supported by Medical Science Research Project of Hebei Provincial Health Commission (grant number 20210055), and Science Technology Plan of Baoding Municipal Department of Science and Technology (grant number 1951 ZF091 and 2041ZF172). The funders had no roles in data collection, decision to publish, or preparation of the manuscript.

\section{Authors' contributions}

Data curation: T.H.Xie, S.J. Cheng.

Funding acquisition: T.H.Xie, X.X.Ren.

Investigation: X.L. Sun, X.J Ren, J. Zhang.

Writing-original draft: T.H.Xie, S.J. Cheng, Y. Fun,.

Writing-review \& editing: T. H. Xie, X.S.Jin,

\section{Acknowledgements}

None.

\section{References}

1. paziogas B, Lazaridis CH, Makris J, Koutelidakis J, Patsas A, Grigoriou M, Chatzimavroudis G, Psaralexis K, Atmatzidis K. Tension-free repair versus modified Bassini technique (Andrews technique) for strangulated inguinal hernia: a comparative study. Henia. 2005;9:156-9.

2. HerniaSurge Group. International guidelines for groin hernia management. Hernia. 2018;22:1-165.

3. Van Veenendaal N, Simons M, Hope W, Tumtavitikul S, Bonjer J, HerniaSurge Group. Consensus on international guidelines for management of groin hernias. Surg Endosc. 2020;34:2359-77.

4. Bozkurt MA, Gönenç M, Kocataş A, Temizgönül KB, Unsal MG, Aliş H. Is laparoscopy needed for incarcerated hernias that became reducible during induction of general anesthesia? Am Surg. 2015;81:E52-3.

5. Sgourakis G, Radtke A, Sotiropoulos GC, Dedemadi G, Fouzas I, Karaliotas C. Assessment of strangulated content of the spontaneously reduced inguinal hernia via hernia sac laparo-scopy: preliminary results of a prospective randomized study. Surg Laparosc Endosc Percutaneous Tech. 2009;19:133-7.

6. Tebala GD, Kola-Adejumo A, Yee J. Hernioscopy: a reliable method to explore the abdominal cavity in incarcerated or strangulated inguinal hernias spontaneously reduced after general anaesthesia. Hernia. 2019;23:403-6. 
7. Mancini R, Pattaro G, Spaziani E. Laparoscopic trans-abdominal pre-peritoneal (TAPP) surgery for incarcerated inguinal hernia repair. Hernia. 2019;23:261-6.

8. Köckerling F, Simons MP. Current concepts of inguinal hernia Repair. Visc Med. 2018;34:145-50.

9. Birindelli A, Sartelli M, Di Saverio S, Coccolini F, Ansaloni L, van Ramshorst GH, Campanelli G, Khokha V, Moore EE, Peitzman A, Velmahos G, Moore FA, Leppaniemi A, Burlew CC, Biffl WL, Koike K, Kluger Y, Fraga GP, Ordonez CA, Novello M, Agresta F, Sakakushev B, Gerych I, Wani I, Kelly MD, Gomes CA, Faro MP Jr, Tarasconi A, Demetrashvili Z, Lee JG, Vettoretto N, Guercioni G, Persiani R, Tranà C, Cui Y, Kok KYY, Ghnnam WM, Abbas AE, Sato N, Marwah S, Rangarajan M, Ben-Ishay O, Adesunkanmi ARK, Lohse HAS, Kenig J, Mandalà S, Coimbra R, Bhangu A, Suggett N, Biondi A, Portolani N, Baiocchi G, Kirkpatrick AW, Scibé R, Sugrue M, Chiara O, Catena F. 2017 update of the WSES guidelines for emergency repair of complicated abdominal wall hernias. World J Emerg Surg. 2017;12:37.

10. Atila K, Guler S, Inal A, Sokmen S, Karademir S, Bora S. Prosthetic repair of acutely incarcerated groin hernias: a prospective clinical observational cohort study. Langenbeck's Arch Surg. 2010;395:563-8.

11. Köckerling F, Alam NN, Antoniou SA, Daniels IR, Famiglietti F, Fortelny RH, Heiss MM, Kallinowski F, Kyle-Leinhase I, Mayer F, Miserez M, Montgomery A, Morales-Conde S, Muysoms F, Narang SK, Petter-Puchner A, Reinpold W, Scheuerlein H, Smietanski M, Stechemesser B, Strey C, Woeste G, Smart NJ. What is the evidence for the use of biologic or biosynthetic meshes in abdominal wall reconstruction? Hernia. 2018;22:249-69.

12. Lee L, Mata J, Landry T, Khwaja KA, Vassiliou MC, Fried GM, Liane S, Feldman LS. A systematic review of synthetic and biologic materials for abdominal wall reinforcement in contaminated fields. Surg Endosc. 2014;28:2531-46.

13. Nie X, Xiao D, Wang W, Song Z, Yang Z, Chen Y, Gu Y. Comparison of porcine small in- testinal submucosa versus polypropylene in open inguinal hernia repair: A systematic review and meta-analysis. PloS One. 2015;10:e0135073.

14. Fang Z, Ren F, Zhou J, Tian J. Biologic mesh versus synthetic mesh in open inguinal hernia repair: system review and metaanalysis. ANZ J Surg. 2015;85:910-6.

15. Hunter JD III, Cannon JA. Biomaterials: so many choices, so little time. what are the differences? Clin Colon Rectal Surg. 2014;27:134-9.

16. Franklin ME Jr, Gonzalez JJ Jr, Michaelson RP, Glass JL, Chock DA. Preliminary experience with new bioactive prosthetic material for repair of hernias in infected fields. Hernia. 2002;6:171-4.

17. Franklin ME Jr, Gonzalez JJ Jr, Glass JL. Use of porcine small intestinal submucosa as a prosthetic device for laparoscopic repair of hernias in contaminated fields: 2-year follow-up. Hernia. 2004;8:186-9.

18. FitzGerald JF, Kumar AS. Biologic versus synthetic mesh reinforcement: what are the pros and cons? Clin Colon Rectal Surg. 2014;27:140-8.

19. Schneeberger S, Phillips S, Huang LC, Pierce RA, Etemad SA, Poulose BK. Cost-utility analysis of biologic and biosynthetic eesh in ventral hernia repair: When Are They Worth It? J Am Coll Surg. 2019;228:66-71.

\section{Figures}



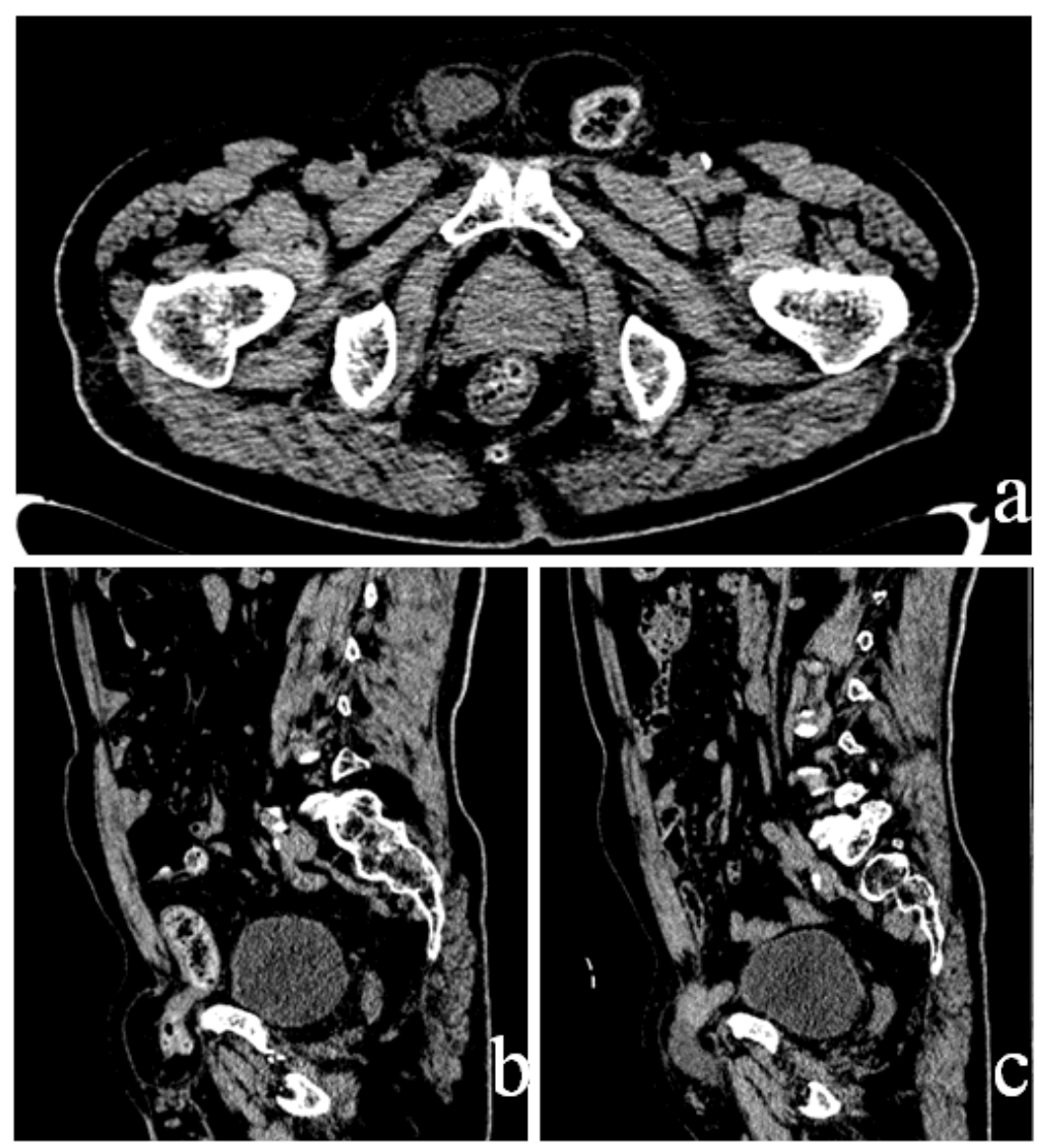

Figure 1

CT showing: a) bowel tissue herniation into both inguinal canal b) the left side $c$ ) the right side 


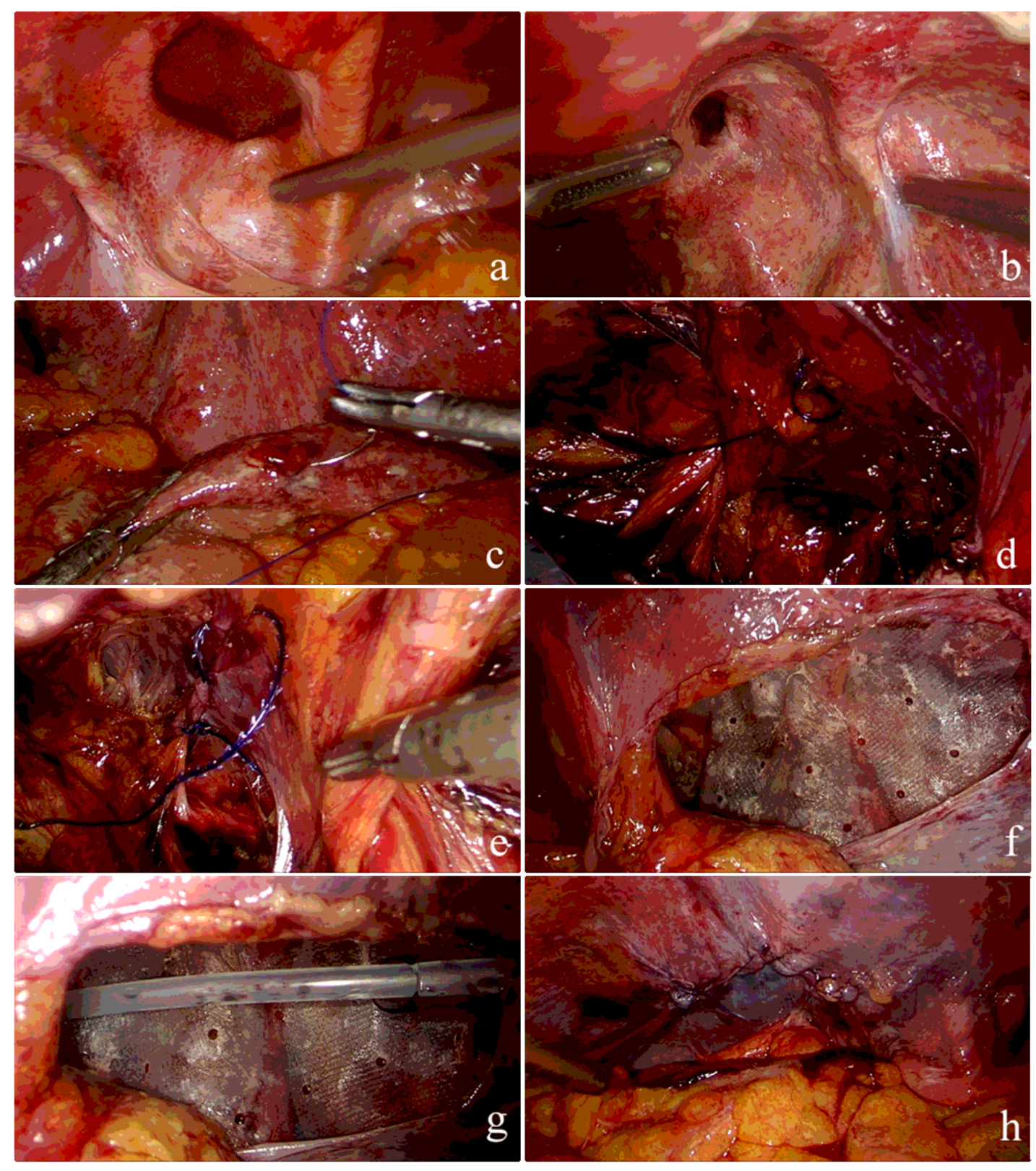

\section{Figure 2}

Laparoscopic examination and treatment: a) the left hernia ring b) the right hernia ring c) suturing the small intestinal perforation d) suturing the left hernia ring e) suturing the right hernia ring $\mathrm{f}$ ) placement of biologic mesh $\mathrm{g}$ ) placement of a drainage tube between the peritoneum and mesh $\mathrm{h}$ ) closure of peritoneum 


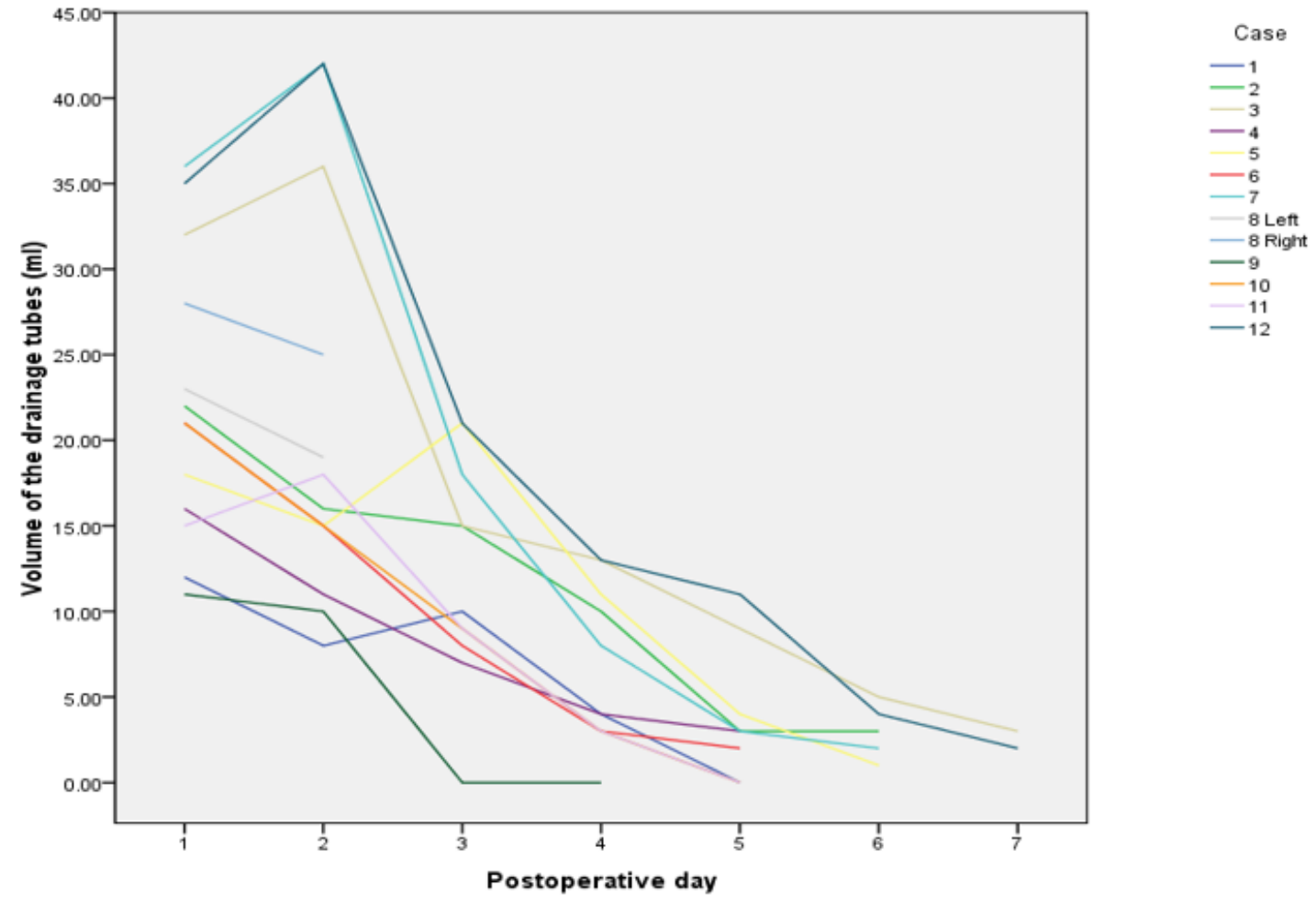

Figure 3

Postoperative time course of volume of the drainage tubes placed between the peritoneum and mesh 